lieves in sewing each perforation as he finds it, making as thorough an examination with as little exposure of the viscera as possible, and after careful sponging, closing the peritoneal cavity tight. By this means better results will be obtained than by drainage, which unquestionably lowers the resistance of the peritoneum. No chance should be left for external contamination.

Dr. R. Wrissow said that handling the intestines is not good practice, if it can be avoided. As to washing out the peritoneal cavity, if there has been but little contamination, certainly not, but if there has been a great deal of soiling, as for example, with beer, food, feces, etc., plenty of water should be used. $\mathrm{He}$ is convinced that these cases should be drained.

\section{THE DENTISTRY OF TO-MORROW.*}

\section{H. P. CARLTON, D.D.S. SAN FRANCISCO.}

Several years ago $I$ had the opportunity to read before the Odontographic Society of Chicago a paper on "University Training and Dental Education," in which I took the ground that dentistry would only be a full profession and recognized as such when the character of the men who comprised it brought its recognition up to what it should be; that as this increase in dignity and professional status must come from within the body of the profession itself, a high grade of young men must be added to its ranks. I outlined the demands of the day and the way to meet those demands, making a plea for better educated material with which to begin our dental training, claiming that with these superior men we could shut the doors of our profession against the trifler and the tinker, and reserve the training of our schools for those who brought to the work the instincts, traditions and outlook of the scholar; the result, real doctors of dental surgery.

I look on this occasion and this paper as but another chance to express my thoughts, to take another step forward, and to prophesy what seems to me the inevitable outcome. If dentistry is to continue to advance, along what lines must it go? It is pretty well conceded thit mechanically we are close to the top notch, and only moderate advance can be looked for in that direction. The advance must then be along scientific lines, higher education and the encouragement of research and investigation.

Dentistry is a specialty of medicine, but the only specialty not universally requiring the degree of doctor of medicine. Indeed, dentistry should be one of the most important branches or specialties of medicine, for in the mouth begin all those processes of nutrition and metabolism which of recent years have attracted so much attention. Thus far neither the physician nor the dentist has given enough scientific study to this special area of the human anatomy, and neither knows what the other has been doing or learning or is doing and learning.

Medicine and dentistry, though cognate sciences, have always been separately studied. This disassociation is now seen to be a great error, due not alone to the fact that the relation of the mouth and teeth to the rest of the anatomy was not understood, but also because only the mechanical aspect probably appealed to thase who first considered the matter; no doubt dentistry had its beginning in the pulling of a tooth. This conception of dentistry as an entity and not as an integral part of medicine has made it an art, possibly a trade, rather than a science. A correct appreciation of phy-

- Read in the Section on Stomatology of the American Medleal Association, at the Fifty-sixth Annual Session, July, 1905. siology, pathology and bacteriology-pluysiology representing the normal relation between the mouth and the rest of the alimentary canal; pathology showing the relation between the deranged functions of the mouth and abnormal conditions of other portions of the alimentary system; and bacteriology as an outgrowth of the study of pathology, showing the causes of the pathologic conditions of the mouth-necessitates an entirely different attitude and is rapidly bringing the child, dentistry, back to its real parent, medicine. It has been said that "Dental science has brought the diseases of the mouth, jaws and teeth so obviously under the domain of general pathology, that somatic problems elsewhere presented in the body are best and easiest studied in the mouth."

The opportunities of modern dentistry are so new and vast that not only is more manipulative skill demanded, but ampler education, more insight, more sagacity, faculties to whose development nature and elaborate training must both contribute. And this training must be given under the guidance of scientific teachers, nonpractitioners, men of productive scholarship, men who devote their lives to the special work of teaching the various subjects which are embodied in a medical education, instead of by those who give instruction during the intervals of a busy practice.

There are new duties calling for a high degree of disciplined intelligence; to quote a recent article, "The knowledge of life and disease represented by the average D.D.S. degree is certainly deplorably deficient." How are we to remedy this? Give our young men a thorough medical training. Dentists are specialists only in their own handiwork, but the ground work is uniform and the demand for individualized education emphasizes the whole difference in our chosen tasks and ignores the great similarities. The technic of our branch of the profession, then, appears only as a small variation of the work in which we all share. The higher the level on which professional specialization begins, the more effectjve it is. And, again, "The higher the profession, the more nearly is the whole man working in every act and the more, therefore, is a broad general education necessary."

How well I remember Professor Joe Le Conte's likening of the modern system of education to the great sequoia, in which the primary and secondary schools were the rootlets and roots, the college culture courses the great bole, and the coming out from it at various altitudes as specializing branches, were the group of professional schools that make up the university. The trunk thus dividing grew higher and smaller, but persisted as the principal member all the way, until the topmost reach of pure culture was highest of all. Specializing without culture he likened to the low-branching bush, with no hope of reaching any fair height, and that the great branch of this tree of knowledge that deals with the study and care of the human body shouid spring from the main trunk after a considerable height of culture, at least that of the college curriculum, which Dr. Le Conte likened to the unbranching trunk, was the contention made in the former paper already mentioned. Without this no standing among the learned professions can be had at all. The half-light of the forest depth can not be grown out of at any less altitude.

It is equally clear, also, that the great branch, the study of the human frame I have spoken of, must go ont from the culture trunk of the university tree as a whole. The least consideration of its logical relations to the 
general culture and to other branches of knowledge will show the justness of this statement. And, having thus gone out from the main trunk, there is plenty of room for a considerable outward and upward reach of this great branch before it begins to subdivide into the various specialties, as the care of the various portions of the human body. So viewed, the mouth has as much relation to medical science, as a whole, as has the care of the eye, the ear, or, indeed, any other organ or group of organs.

He would be a superfieial reasoner who would deny the great culture value of the medical course. Dr. Le Conte himself found it a firm foundation in its hold on physics and chemistry and a whole group of other sciences, and yet more in its cultivation of the habits of scientiiic observation of facts and logical reasoning from them for the stately structure of his own scientific attainments. The man who has taken it is a doctor, with none of the weakening qualifications of D.D.S., connoting a lesser scientific rank.

Most dental schools of the present time are at the mercy of the demands of the day and age, and their students are the product of the surroundings, not the choice of the school. An ideal professional school would be one that exists for its work alone, for scientific investigation and practical instruction not given by busy wage earners.

The dentist of to-morrow can not be the same sort of man as the dentist of the past, whose own little sphere has been bounded by thirty-two teeth. He must be the carefully educated student in the medical branches, plus the dental specialties, and you can only make him so by following the same educational plan as in preparing the doctor of medicine. Without the requisite medical edncation, the ordinary mechanically expert dentist is not competent to practice his profession-he can only exercise a mechanical dexterity, but with the proper education he not only exercises the same dexterity, but he has professional ability.

The mouth is a fairly good barometer of the whole system, but your merely mechanical man, as contrasted with the dental specialist in medicine, is not competent to read it, and he does not. Why? How can any man untrained in medical science understand the problems presented to him in the condition of the mouth? We all know how exceedingly often some affection of the mouth or teeth is but an indication of a general systemic disturbance of metabolism; and, on the contrary, how frequently we see a faulty dental anatomy causing nutritive derangements which are puzzling to the physician who is ignorant of the large part played by the mouth in general alimentation. These things can not be comprehended by the merely mechanically trained dentist, as distinguished from the dental specialist, any more than they are intelligible to the physician whose training has omitted all reference to the mouth as a vital part of the alimentary canal. He who would in the future confine his professional work to conditions involving the mouth and teeth-the dental specialist - must be a broad diagnostician; he must know the relation of the mouth to the general system and he must interpret what he sees in the mouth in the light of his general medical education.

To bring about this condition-a condition which must surely come with the passage of time the same preliminary training in the academic sciences will be required, whether the student intends to practice general medicine or surgery, or to specialize along the lines of ophthalmology, dermatology, orthopedic surgery or dentistry.

The same general medical education must also be required, no matter to what special region of the anatomy nor to what special line of work the student intends to confine himself eventually.

What will be the results of this medical education? When this is accomplished what is going to become of your dentist? Practical life demands a division of labor; therefore, the specializing of the individual. There will be a division of the product just as in general medicine, and the natural ability of the individual will show itself. Some are going on plugging teeth, but better able, not less equipped for that work, for this higher education is not a question alone of preparing great men for great things; it must also prepare little men for greater things than would otherwise have been possible. Another lot are going to take up broad scientific work and research-not merely the mouth, but the mouth as merely a part, and the world will be spared from lots of trouble. But he who takes up the mechanical side of dental medicine has a broad and an inviting field of work before him. Thus far the orthopedic surgeon and the ophthalmologist who confines himself to refraction are most highly skilled mechanical specialists in medicine, but the medical dentist of the future will stand with them.

Consider the remarkably high degree of mechanical skill developed in the proper adjustment of a plaster jacket! Think of the tremendously complex Wullstein apparatus, devised for this purpose, and consider a man with no mechanical skill, in spite of any amount of medical education, attempting to apply such a jacket!

Dentistry, as well as orthopedic surgery, requires this highest kind of mechanical ability-take the apparatus used in orthodontia, for example; its construction and application call for the best mechanical skill, but they need back of that the academic training, or they don't reach the elevation. 'The real professional man' should possess the resources of a highly developed, reasoning faculty, which comes only after years of systematic pursuit of what might be called higher or university study. It is this broad mental training that makes better dentists and better men. We are not only professional wage earners-we live for our friends and our nation; we are in contact with nature and science, with art and literature; we shape our town and our time. Let us, then, provide the kind of men who know how to think.

Imagine a profession of mere operators; professional men! Not so; mechanical artisans. The hope of the profession lies not in fitting a system of instruction to the capacity of unpromising students, not in "substituting intellectual milk for intellectual meat, aye, even in giving this milk in small quantity because of the puniness of the babes; but in choosing students equal to the requirements of an advanced method of instruction and substituting capable men for the class that now fill our colleges."

Turning out men with broad, well-balanced minds, with the faculty of judgment, strengthened by the mastery of principles rather than the acquisition of informittion. So much of the groundwork of medicine and dentistry is held in common that it is a wasteful folly to teach it in separate schools rather than in one wellequipped and well-manned institution. The cutting out of this unnecessary duplication of work is the spirit of the age and the method of much that we call our moilern advance. 
To summarize this point: The things that are purely ground work, physics, inorganic chemistry, and all the branches that make for the building up of the man able to see clearly, to imagine vividly and to reason correctly, as Dr. Henry Van Dyke puts it-these should be given in college. 'Then, all the studies necessary to the understanding of the human anatomy, physiology and hygiene should be taken in a medical course; then, and then alone, is it time to specialize on oral surgery to make a dentist. It used to be said of Cuvier that, given a single bone, he could construct a whole animal, but he never arrived at that point by the study of one kind of bones only. Rather it is the method of to-day to study the whole skeleton, yes, and all the other parts of an animal as well, in order to understand one bone.

"Great truths approach slowly and dwell a long time with small minorities." Progress is the law of this American race, which stands for all that's best; truly it is a race which knows no rest. Was it not Macaulay who said, "A standing point which was yesterday invisible is the goal to-day and will be the starting post of tomorrow?"

\section{WHAT WILL PROBABLY BE THE DENTAL EDUCATIONAL STANDARD FOR THE COMING DECADE ?* \\ CHARLES C. CHITTENDEN, D.D.S. MADISON, WIS.}

At the last meeting of this Section, at Atlantic City, in 1904, a symposium on dental educational standards was read, which was exhaustive and thorough in its character. In a paper presented at that symposium I had the honor to report chronologically the various facts as they had transpired, during the current year, concerning the attitude of the individual dental schools and the National Association of Dental Faculties toward the newly inaugurated four years' college course.

It had become apparent that a large number of the smaller and financially hampered schools were determined on returning to the three years' course.

This Section, at that time, in its discussions, expressed, in no uncertain terms, its entire disapproval of any such retrograde action.

Immediately following the meeting of this Section came the annual meeting of the National Association of Dental Faculties at Washington, D. C., where the whole subject was gone over and discussed very exhaustively, with the final result that, by a close vote of twenty-four to twenty-one colleges, the four years' course was upheld. This occurred in the early part of June. Almost at once following the adjournment the ad interim committee began to receive the resignations from membership in the National Association of Dental Faculties of a number of schools which were opposed to the decision at Washington to continue the four years' course. These resignations created such a panic in the ranks of the colleges that the ad interim committee was finally induced to call a special meeting of the National Association of Dental Faculties to be held at St. Louis, July 18,1904 , whose sole purpose should be a reconsideration of the final decision made at Washington, the month previous, to continue the four years' course.

At this special meeting there were, of the fifty-one colleges in membership, twenty-eight represented. By a vote of 26 to 2 (being by a majority of one of the

* Read in the Section on Stomatology of the American Medical Association, at the Fifty-sixth Annual Session, July, 1905. total membership) the four years' course was revoked and a three years' course of thirty weeks in each year was adopted in its place. The public announcement of this distinctly retrograde step (taken by a bare majority of one of the membership of the college association) came as a distinct shock to the rank and file of the profession. There was no semblance of an off-set in the way of increased standard requirements for admission to the college course to, in some measure, soften the baldness of the action. The outside world was simply made suddenly aware that the National Association of Dental Faculties, without waiting to graduate a single class or man under the vaunted higher educational system which that body had spent at least three years in elaborating, and had then declared to the world as absolutely necessary to properly fit the student for the dental degree, had, without explanation, struck its colors and surrendered. The one saving phase of the whole transaction was the fact that practically one-half of our colleges had been opposed to the change and had only acquiesced in it "to save the Faculties Association."

The examiners of the United States had been loyally standing behind and ready to protect the schools in their higher standards in every way. To them this bold retrogressive step called for immediate action. A blow had been struck, for commercial reasons only, at the established standards, and struck, too, by our National Association of Dental Faculties! All the schools of the better class had been obliged to yield to the inevitable and lower their standards-all save one, whose noble independence but makes the situation appear the more pathetic.

The annual meeting of the National Association of Dental Examiners was held late in August, 1904, at St. Louis. It was apparent, from the first news of the "retrogression," that something must be done to retrieve the situation before the world, and the examiners rose at that meeting to the occasion. The following report from the committce on colleges, preceded by a careful résumé of the entire situation, was unanimously adopted :

Your committee would therefore recommend that this association establish at once, to go into operation not later than the opening of the school year of 1905-6, the educational requirements, for admission to the dental college course, of graduation from an aceredited high school or its full equivalent, all examinations of credentials and equivalents to be placed in the hands of an acceptable appointee of the state superintendent of public instruction where not otherwise provided for by law.

In view of the present disturbed and unsettled conditions existing in dental educational circles, and with a belief in avoiding all unnecessary disturbances of standards at this time, your committee would further recommend that no change be made at this time in the present requirements of this association of not less than 28 calendar months of college attendance for graduation.

By what had occurred the trust of the examiners in the ability of the college association to maintain good faith under certain exigencies was so badly shaken that all standing resolutions which in any way interfered were rescinded, and the committee on colleges was instructed to prepare a new list of recommended colleges, based on the acceptance by the individual schools of the standards declared in the above report. The work was to be done independently of the National Association of Dental Faculties.

After having spent many months in correspondence and careful conferences with many of our ablest teachers and scientists, the committee on colleges issued the fol- 